\title{
Jusual llemiat \\ ODDIM \\ SUATU KAJIAN TERHADAP KEBERADAAN BIDAN DESA DAN DUKUN BAYI DI DESA MARISI KECAMATAN ANGKOLA TIMUR KABUPATEN TAPANULI SELATAN
}

\author{
Soritua Ritonga \\ Universitas Muhammadiyah Tapanuli Selatan \\ Email : fisipumts@gmail.com
}

\begin{abstract}
Abstrak
Masyarakat Desa Marisi masih ada yang menggunakan jasa dukun bayi dalam proses persalinan, mengingat akan bahayanya persalinan dengan dukun bayi karena tidak memiliki keahlian yang terlatih dan terutama untuk masalah obat-obatan dan pemeriksaan kandungan. Akan tetapi masyarakat masih saja ada yang menggunakan jasa dukun bayi. Desa Marisi sendiri memiliki tenaga kesehatan ahli untuk persalinan yaitu bidan, namun keberadaan bidan sendiri masih belum memiliki pengaruh bagi masyarakat agar tidak menggunakan jasa dukun bayi.

Keberadaan bidan desa dan dukun bayi dalam proses persalinan di Desa Marisi sama-sama sangat dibutuhkan oleh masyarakat. Jasa Bidan merupakan tenaga persalinan yang terlatih dan didukung oleh ilmu medis, peralatan kesehatan serta obat-obatan. Sehingga memberi rasa aman dan keselamatan yang maksimal bagi masyarakat yang ingin melakukan persalinan.

Sedangkan dukun bayi merupakan tenaga persalinan yang keahliannya diperoleh dari turun-temurun, dan menjadi alternatif pilihan masyarakat yang ingin melakukan persalinan karena biaya persalinan yang relatif murah, bisa dibayar dengan barang, dekat dengan pemukiman dan bisa dipanggil ke rumah masyarakat. Faktor-faktor yang membuat masyarakat memilih dukun bayi dalam persalinan yaitu : faktor ekonomi, jarak tempuh bidan yang jauh dari pada dukun, pendidikan masyarakat yang cukup rendah, kebiasaan masyarakat sejak dahulu secara turun menurun.
\end{abstract}

Kata kunci : bidan desa, dukun bayi

\section{Abstract}

Marisi village community still uses the services of TBAs in the delivery process, considering the danger of labor with a TBA because they lack trained expertise and especially for medicinal and obstetric problems. However, there are still people who use the services of TBAs. Marisi village itself has a skilled health worker for the delivery of midwife, but the presence of midwife itself still does not have an influence for the community to not use the services of a TBA.

The existence of village midwives and midwives in the process of childbirth in the village of Marisi equally very needed by the community. Midwife Services is a trained labor force supported by medical science, medical equipment and medicines. So as to provide maximum security and safety for people who want to do the delivery.

While the TBA is a birth attendant whose expertise is gained from generation to generation, and becomes an alternative choice of people who want to do the delivery because the cost of labor is relatively cheap, can be paid with goods, close to the settlement and can be called to the community home. Factors that make people choose dukun baby in childbirth are: economic factor, distance of midwife far from dukun, society education which is low enough, habit of society since long time down down.

Keywords: shaman child, village midwife

\section{PENDAHULUAN}

Angka kematian ibu di Indonesia masih tergolong cukup tinggi, salah satu penyebabnya adalah karena proses persalinan, sampai saat ini permasalahan tersebut belum mampu di atasi oleh pemerintah pusat maupun pemerintah daerah. Meskipun berbagai program telah dikeluarkan oleh pemerintah namun angka kematian ibu masih saja tinggi.

Penyebab langsung kematian ibu adalah perdarahan, yang diakibatkan oleh proses persalinan ibu hamil. Banyak ibu hamil saat melewati proses persalinan tidak bisa melaluinya dengan sempurna dan tidak jarang mengakibatkan kematian ibu dan bayi. Kasus seperti ini banyak terjadi di daerah daerah yang ada di Indonesia.

Salah satu faktor penyebabnya adalah kurangnya tenaga kesehatan dan fasilitas kesehatan dalam persalinan seperti bidan dan puskesmas di daerah-daerah yang ada di Indonesia masih banyak yang kekurangan tenaga bidan untuk persalinan. Meskipun program penempatan bidan desa ke daerah terpencil sudah berjalan namun 
belum seutuhnya dilakukan secara maksimal, ini terjadi hampir di seluruh daerah yang ada di Indonesia.

Termasuk di daerah Kabupaten Tapanuli Selatan, berdasarkan data profil Dinas Kesehatan Kabupaten Tapanuli Selatan tahun 2015 Kecamatan Angkola Timur yang menjadi daerah kecamatan fokus penelitian Tahun 2015 memiliki sarana kesehatan sebagai berikut :

Puskesmas Non Perawatan sebanyak 2 unit, Puskesmas Pembantu 4 unit, Puskesmas Keliling 2 unit, Balai Pengobatan Swasta 1 unit, Polindes 3 unit, Posyandu 46 unit, dan Poskesdes 4 unit. Tenaga Kesehatan Dokter 3 orang dan Sarjana Kesehatan Masyarakat 4, Bidan 25 orang, Bidan PTT 29 orang. (Badan Pusat Statistik Tapanuli Selatan, 2016: 98-102)

Berdasarkan data tersebut tidak sebanding dengan jumlah desa/kelurahan yang ada di wilayah Kecamatan Angkola Timur Kabupaten Tapanuli selatan yang memiliki 13 desa dan 2 kelurahan. Tentunya masih butuh perhatian yang lebih dari pemerintah Kabupaten Tapanuli Selatan dalam memenuhi fasilitas kesehatan untuk masyarakat.

Masih

pertolongan

rendahnya cakupan diantaranya adalah bahwa masyarakat masih ada yang mempercayai dukun bayi dibandingkan dengan bidan karena pelayanan dukun dinilai lebih komprehensif, lebih murah dan mudah dipanggil kerumah. Sedangkan tempat fasilitas persalinan jauh dijangkau oleh masyarakat sehingga masyarakat masih mengandalkan jasa dukun bayi.

Keberadaan dukun tidak terlepas dari masalah yang berkaitan dengan sistem kepercayaan karena masyarakat mempunyai kepercayaan untuk menerima suatu pernyataan atau pendirian tanpa menunjukan sikap pro dan kontra. Maka dari itu masyarakat lebih mudah memilih melakukan persalinan kepada dukun karena sejak dulu tenaga kesehatan khususnya untuk persalinan masih minim.

Masyarakat yang ada di Desa Marisi Kecamatan Angkola Timur Kabupaten Tapanuli Selatan masih menggunakan jasa dukun bayi dalam menangani kesehatan ibu dan bayi. Penanganan kesehatan yang dilakukan oleh dukun bayi adalah pelayanan kesehatan pasca kelahiran, sehingga tidak dapat dipungkiri masyarakat Desa Marisi masih menganggap penting keberadaan dukun bayi dalam menangani masalah persalinan.

Faktor-faktor yang menjadi penyebab dukun bayi masih memiliki peran dan kedudukan di Desa Marisi menurut pengamatan penulis adalah faktor ekonomi karena biaya ke dukun bayi lebih murah jika dibanding dengan bidan, faktor jarak karena keberadaan bidan sangat jauh dari rumah mereka maka masyarakat lebih memilih dukun bayi, kemudian kurangnya tenaga bidan yang ada di desa ini serta kepercayaan masyarakat yang sejak lama masih mempercayai dukun bayi sebagai tenaga persalinan.

Keberadaan bidan desa sebagaimana program yang dicanangkan oleh pemerintah bahwa dukun bayi dapat membantu persalinan dengan bidan desa yang tertuang dalam program kemitraan bidan desa dan dukun bayi selama ini tidak berjalan dengan baik terutama di Desa Marisi karena masyarakat di sini masih ada yang menggunakan jasa dukun bayi. Meskipun proses persalinan yang dilakukan oleh dukun bayi lebih membahayakan keselamatan sang ibu karna kurangnya peralatan dan obat-obatan.

Perawatan persalinan yang dilakukan oleh bidan lebih higienis dan aman serta peralatannya lengkap dan juga obatobatannya, namun masyarakat sekitar masih ada yang memilih jasa dukun bayi dalam persalinan, sudah tentu resikonya lebih besar dari pada bidan. Untuk itu, perlu adanya sosialisasi kepada masyarakat mengenai keberadaan bidan dan dukun bayi dalam proses persalinan.

\section{Perumusan Masalah}

Berdasarkan dari uraian latar belakang masalah di atas maka rumusan masalah dalam penelitian ini adalah sebagai berikut :

1. Bagaimana keberadaan bidan desa dan dukun bayi dalam persalinan di Desa Marisi Kecamatan Angkola Timur Kabupaten Tapanuli Selatan?

2. Faktor apa saja yang menyebabkan masyarakat di Desa Marisi Kecamatan Angkola Timur Kabupaten Tapanuli Selatan lebih dominan memilih dukun bayi dalam persalinan?

\section{Tujuan}

Berangkat dari rumusan masalah di atas maka yang menjadi tujuan yang ingin dicapai adalah :

1. Untuk mengetahui keberadaan bidan desa dan dukun bayi dalam persalinan di Desa Marisi Kecamatan Angkola Timur Kabupaten Tapanuli Selatan

2. Untuk mengetahui faktor apa saja yang menyebabkan masyarakat di Desa Marisi Kecamatan Angkola Timur Kabupaten Tapanuli Selatan lebih dominan memilih dukun bayi dalam persalinan.

\section{Tinjauan Teoritis \\ Bidan}

Sejarah menunjukan bahwa kebidanan merupakan salah satu profesi tertua di dunia sejak adanya peradaban umat manusia. Bidan lahir sebagai perempuan terpercaya dalam mendampingi dan menolong ibu yang melahirkan. Profesi 
ini telah mendudukkan peran dan posisi seorang bidan menjadi terhormat di masyarakat karena tugas yang di embannya sangat mulia dalam upaya memberikan semangat dan membesarkan hati ibu.

Bidan merupakan profesi yang diakui secara nasional dan internasional dengan sejumlah praktisi di seluruh dunia. Menurut WHO bidan adalah seorang yang diakui secara reguler dalam program pendidikan bidan, diakui secara yuridis ditempatkan dan mendapat kualifikasi serta terdaftar di sektor dan memperoleh izin melaksanakan praktik kebidanan. (Mufdilah, 2012 : 18)

Bidan menurut Peraturan Menteri Kesehatan Republik Indonesia Nomor 1464 Tahun 2010 Tentang ljin dan Penyelengaraan Praktik Bidan adalah seorang perempuan yang lulus dari pendidikan bidan yang telah teregristrasi sesuai ketentuan peraturan perundangundangan. Bidan adalah seseorang yang telah menjalani program pendidikan bidan, yang diakui oleh negara tempat ia tinggal, dan telah berhasil menyelesaikan studi terkait kebidanan serta memenuhi persyaratan untuk terdaftar dan atau memiliki izin formal untuk praktik bidan.

Bidan dikenal sebagai professional yang bertanggung jawab yang bekerja sebagai mitra perempuan dalam memberikan dukungan yang diperlukan, asuhan dan saran selama kehamilan, periode persalinan, dan postpartum, melakukan pertolongan persalinan di bawah tanggung jawab sendiri, serta memberikan perawatan pada bayi baru lahir.

Bidan merupakan seorang yang menjaga ibu dengan sabar dan penuh cinta, meraba dan menyentuh dengan penuh sensitif dan sopan, mendengarkan dengan penuh perhatian, dan memberikan waktu yang memadai, mencium dengan penuh pengertian dan perhatian. Kemampuan seorang bidan untuk menjadi pendamping perempuan dan keluarganya merupakan perpaduan dan kepribadian.

\section{Dukun Bayi}

Dukun bayi adalah pelayan kesehatan yang mempunyai tujuan sama seperti bidan namun berbeda dalam hal penanganan. Jika bidan menangani persalinan dengan menggunakan keahlian medis dan di fasilitasi oleh alat-alat medis yang modern, maka berbeda halnya dengan cara kerja dukun bayi. Dukun bayi bekerja dengan cara dan alat yang masih sederhana.

Dukun bayi biasanya persalinan dilakukan dengan duduk di lantai di atas tikar, dukun yang menolong menunggu sampai persalinan selesai. Ibu dikerumuni orang yang lebih tua (keluarga dan tetangga), didekatnya ada tempat berisi air yang sebentar-bentar di isi uang logam yang nantinya diperuntukan dukun. Ibu bersalin tidak boleh makan dan minum sampai selesai, semua benda yang tertutup harus dibuka. Cara bekerja dukun dengan mengurut-urut perut ibu bayi, menekannya serta menarik anak apabila anak telah kelihatan.

Selama menolong dukun banyak membaca mantra-mantra. Pemeriksaan dalam kadang dilakukan untuk mengetahui turunnya anak. Setelah lahir anak diciprati dengan air/dikejutkan dengan memukul suatu benda agar menangis. Tali pusat dipotong setelah bayi lahir dengan sembilu atau bambu kemudian tali pusatnya diberi ramuan kunyit, abu tempurung dibungkus daun sirih sebagai disenfektan. Plasenta diberi ramuan, ditanam dengan upacara, selama 7 hari diberi lampu (agar plasenta pada malam hari tidak susah mencari jalan untuk menjaga bayi). Bayi dipaikan gurita, badan diulas dengan ramuan, bayi dibedong, minuman yang pertama air kelapa muda/madu, sudah diberi makan pisang dan nasi yang dihaluskan kemudian disusui. Bayi tidak dimandikan sampai tali pusat lepas.

Setelah bersalin ibu dimandikan oleh dukun selanjutnya ibu sudah harus bisa merawat dirinya sendiri lalu ibu diberikan juga jamu untuk peredaran darah dan untuk laktasi. Cara ibu tidur setengah duduk agar darah kotor lekas keluar. Ibu masa nifas tidak boleh minum banyak. Bayi diurut baru dimandikan oleh dukun selama 40 hari, ramuan tali pusat tiap hari diganti sampai putus. Tali pusat yang sudah lepas dibuat jimat atau obat. Bayi ditidurkan di samping ibu, tidak boleh dibawa jauh dari rumah sebelum berumur 35 hari. Ubun-ubun besarnya ditutup tapel. (Mufdilah, 2012 : 4748)

Dukun bayi melakukan pemeriksaan kehamilan kepada ibu hamil, dukun bayi bisa menetapkan wanita itu hamil atau tidak, letak anak, kapab bayi akan lahir, mengetahui letak yang salah tapi bisa memperbaiki, memberikan nasehat bagaiman ibu hamil harus hiidup seperti :

1. Melakukan pantangan

a. Pantangan makanan tertentu

b. Pantangan terhadap pakaian

c. Pantangan terhadap jangan pergi malam

d. Pantangan jangan duduk di depan pintu

\section{Kenduri}

Kenduri pertama kali dilakukan pada waktu hamil 3 bulan sebagai tanda wanita itu hamil. Kenduri kedua dilakukan pada waktu umur kehamilan 7 bulan. (Mufdilah, 2012 : 49)

Pada intinya di Indonesia dukun bayi tidak dilarang, karena dukun bayi termasuk pemberian pelayanan kesehatan secara tradisional, asalkan tidak melanggar dari ketentuan agama dan budaya setempat sebagaimana yang diatur dalam UndangUndang Nomor 36 Tahun 2009 Tentang Kesehatan Pasal 59 yang berbunyi berdasarkan cara pengobatannya, 
pelayanan kesehatan tradisional terbagi menjadi pelayanan kesehatan tradisional yang menggunakan keterampilan, dan pelayanan kesehatan tradisional yang menggunakan ramuan.

\section{Persalinan}

Pengertian persalinan merupakan suatu proses pengeluaran hasil konsepsi (Janin dan Uri) yang dapat hidup dari dalam uterus melalui vagina ke dunia luar. Persalinan adalah proses melahirkan dan dibutuhkan tenaga bidan untuk proses persalinan tersebut. Pengertian lainnya tentang persalinan adalah proses pengeluaran hasil konsepsi (janin dan uri) yang telah cukup bulan dan dapat hidup di luar uterus melalui vagina secara spontan. (Prawiharjo Sarwono, 2009 : 35)

Persalinan seperti yang diungkapkan oleh Prawiharjo Sarwono adalah proses pengeluaran hasil konsepsi, yang mampu hidup, dari dalam uterus melalui vagina ke dunia luar. Persalinan merupakan proses kelahiran anak dari perut ibu yang dibantu oleh bidan untuk melahirkan. Kelahiran dilakukan apabila usia kandungan ibu telah mencapai usia 9 bulan. Dengan kata lain persalinan merupakan proses kelahiran bayi yang ada di kandungan sang ibu saat usia kandungan telah berusia 9 bulan. (Prawiharjo Sarwono, 2009 : 180)

Persalinan membutuhkan usaha total ibu secara fisik dan emosional, karena itu dukungan moril dan upaya untuk menimbulkan rasa nyaman bagi ibu bersalin sangatlah penting. Ibu mungkin berada dalam tahapan persalinan dan kondisi yang berbeda-beda satu sama lain, sehingga kebutuhan masing-masing pun berbeda. Perawatan yang diberikan perlu disesuaikan dengan kebutuhan masing-masing ibu.

\section{METODE PENELITIAN}

Penelitian ini menggunakan metode penelitian kualitatif yang menggunakan teknik pengumpulan data berupa hasil pengamatan di lapangan, hasil wawancara dengan responden serta studi kepustakaan yang kemudian di analisis menggunakan teknik analisis kualitatif yang berupa katakata secara naratif sesuai dengan perumusan masalah yang telah ditentukan sebelumnya.

\section{PEMBAHASAN}

Tujuan umum dari pembangunan kesehatan adalah untuk mengusahakan kesempatan yang luas bagi anggota masyarakat untuk memperoleh derajat kesehatan yang sebaik-baiknya dengan mengusahakan pelayanan kesehatan yang lebih luas, lebih merata, yang terjangkau bagi masyarakat terutama yang berpenghasilan rendah baik di desa maupun di kota. Desa Marisi memiliki tenaga kesehatan yaitu 3 (tiga) bidan, dan 1 (satu) orang dukun. Desa Marisi tidak ada fasilitas kesehatan seperti Posyandu, Polindes, dan pelayanan kesehatan lainnya.

Profesi dukun bayi masih banyak digunakan masyarakat Desa Marisi, meski sudah ada jasa bidan penduduk desa masih saja melahirkan ke dukun bayi. Dukun bayi mencerminkan budaya masyarakat. Hingga kini sebagian masyarakat terutama para ibu masih memilih menggunakan jasa dukun bayi untuk membantu proses persalinan. Walaupun sekarang sudah jaman modern masih memerlukan tenaga dukun sebagai pendamping dalam mengawasi kehamilan disaat tenaga bidan tidak bisa melakukan pengawasan secara penuh.

Layanan tersebut sama seperti yang dilakukan dukun bayi di Desa Marisi yang sudah menjalani profesinya selama 16 tahun yaitu Patima Pasaribu. Usianya berkisar 51 tahun memiliki 5 (lima) orang anak, masyarakat banyak yang menggunakan jasanya dalam melahirkan. Bahkan ke-lima anak dari Patima Pasaribu proses persalinannya dibantu dirinya sendiri tanpa bantuan dari bidan desa hanya saja masalah suntikan dan obat-obatan baru dimintai dari bidan untuk obat kekebalan atau pemulihan pasca melahirkan

Selain menjalani profesinya sebagai dukun bayi Patima Pasaribu juga sehari-hari menghabiskan waktunya di sawah dengan menjadi seorang petani, dan membuka warung kopi di rumahnya sendiri yang dijalankan oleh anak-anaknya. Dalam setiap tahunnya dukun bayi ini memperoleh pasien minimal dalam setahun 5 (lima) orang untuk membantu melahirkan ibu hamil. Proses persalinan yang dijalankannya tanpa ada ritual tertentu yang harus dipenuhi oleh pasiennya.

Selama menjalani proses persalinan tidak pernah ada kendala seperti kematian adapun itu terjadi dulu ketika ibu dari dukun bayi ini menjalankan proses melahirkan itupun tidak banyak. Masyarakat atau para ibu hamil sampai saat ini menggunakan jasa dukun bayi untuk menjalinin proses persalinnanya.

Masyarakat di Desa Marisi masih lebih percaya kepada dukun bayi dari pada ke bidan. Masih banyak masyarakat yang memilih persalinan ditolong oleh tenaga kesehatan non medis daripada tenaga kesehatan disebabkan oleh beberapa faktor antara lain tingkat pendidikan yang rendah, status dalam masyarakat terhadap penyuluhan dan pertugas kesehatan rendah dan tingkat kepercayaan masyarakat terhadap penyuluhan dan petugas kesehatan masih rendah.

Pengetahuan tentang bahayanya bersalin dengan dukun bayi tidak begitu dipermasalahkan oleh masyarakat terutama para ibu hamil. Terbatasnya tingkat pendidikan dan kurangnya keterampilan berpengaruh terhadap kurangnya kesadaran dan manfaat pemeliharaan kesehatan, khususnya dalam pemilihan 
proses persalinan. Tingkat pendidikan yang semakin baik akan menjamin kesehatan keluarga yang baik pula. lbu yang berpendidikan lebih, mudah untuk memahami informasi dengan baik terhadap penjelasan yang diberikan oleh petugas kesehatan tentang siapa penolong persalinan yang aman, selain itu yang berpendidikan tidak akan berpengaruh dengan informasi.

Pendidikan ibu berhubungan dengan pemilihan tenaga penolong persalinan mengingat bahwa pendidikan dapat mempengaruhi gaya intelektual seseorang dalam memutuskan suatu hal termasuk penentu pertolongan persalinan. Pendidikan ibu yang kurang menyebabkan daya intelektualnya masih terbatas sehingga perilakunya masih terpengaruhi oleh keadaan sekitarnya ataupun perilaku kerabat lainnya atau orang yang mereka tuakan.

Keberadaan Bidan desa sangat penting terhadap kesehatan ibu dan bayi dalam masa hamil, persalinan sampai pada pasca melahirkan. Bidan desa melakukan penyuluhan ataupun pemeriksaan kandungan ibu hamil per periode yang telah ditentukan, memberikan terapi khusus kepada ibu hamil supaya bayi yang ada bisa sehat dan selamat sampai pada kelahirannya. Begitu juga pasca melahirkan bidan desa memberikan pengobatanpengobatan khusus dalam upaya pemulihan ibu dan anak pasca melahirkan.

Apabila dikaji keberadaan dukun bayi dan bidan di Desa Marisi masing-masing keberadaannya sangat penting, selain proses persalinan bidan desa juga bisa menyembuhkan masyarakat yang sedang sakit masyarakat bisa langsung datang ke lokasi praktik bidan yang ada. Begitu juga dengan dukun bayi selain sebagai persalinan dukun bayi juga bisa menyembuhkan masyarakat yang sakit tentu dengan obat-obatan tradisional.

Keberadaan bidan di Desa Marisi sangat penting untuk pemeriksaan kandungan, proses persalinan dan pasca melahirkan, selain itu bidan juga sebagai tempat masyarakat untuk berobat karena bidan memiliki keahlian khusus selain melakukan persalinan

Masyarakat yang melakukan proses kelahiran dengan bidan masih menganggap bahwa bidan merupakan tenaga ahli kesehatan di bidang persalinan, karena masyarakat tidak mau mengambil resiko besar yang dapat mengakibatkan kematian baik untuk dirinya maupun untuk si bayi.

Dengan faktor pertimbangan masalah keselamatan dan memandang bahwa bidan adalah tenaga kesehatan yang memang ahli dibidangnya menjadi alasan masyarakat sadar dengan melahirkan menggunakan jasa bidan. Faktor ekonomi bukan menjadi alasan bagi sebagian masyarakat karena sekarang sudah ada kartu BPJS Kesehatan untuk biaya persalinan masyarakat yang diberikan pemerintah.

Sebaliknya masyarakat yang masih percaya dengan pengobatan tradisional yang selalu berkaitan dengan praktik-praktik yang dijalankan oleh dukun termasuk pula dukun bayi masih sangat jelas terlihat di Desa Marisi. Keberadaan dukun bayi dalam era modern seperti sekarang ini masih sangat besar pengaruhnya dalam masyarakat.

Begitu pula dengan masyarakat di Desa Marisi yang masih menggunakan jasa dukun bayi dalam penanganan kesehatan bayi maupun ibu. Pada umumnya ibu-ibu di Desa Marisi memiliki kebiasaan melahirkan dengan dukun bayi. Masyarakat yang menggunakan jasa dukun bayi dalam persalinan menganggap dukun bayi sangat penting bagi masyarakat miskin yang ingin melakukan persalinan karena biaya persalinan dengan dukun terjangkau bagi masyarakat. Selain itu keberadaan dukun bayi juga dekat dengan rumah masyarakat dan bisa dipanggil langsung ke rumah masyarakat untuk melakukan persalinan.

\section{KESIMPULAN}

Berdasarkan hasil penelitian di lapangan yang didapatkan melalui hasil wawancara dengan informan, maka kesimpulannya sebagai berikut :

1. Keberadaan bidan desa dan dukun bayi dalam proses persalinan di Desa Marisi sama-sama sangat dibutuhkan oleh masyarakat. Jasa Bidan merupakan tenaga persalinan yang terlatih dan didukung oleh ilmu medis, peralatan kesehatan serta obat-obatan. Sehingga memberi rasa aman dan keselamatan yang maksimal bagi masyarakat yang ingin melakukan persalinan. Sedangkan dukun bayi merupakan tenaga persalinan yang keahliannya diperoleh dari turun-temurun, dan menjadi alternatif pilihan masyarakat yang ingin melakukan persalinan karena biaya persalinan yang relatif murah, bisa dibayar dengan barang, dekat dengan pemukiman dan bisa dipanggil ke rumah masyarakat.

2. Faktor-faktor yang membuat masyarakat memilih dukun bayi dalam persalinan yaitu : faktor ekonomi, jarak tempuh bidan yang jauh dari pada dukun, pendidikan masyarakat yang cukup rendah dan kebiasaan masyarakat sejak dahulu yang sudah turun temurun.

\section{DAFTAR PUSTAKA}

Mufdilah, dkk, 2012, Konsep Kebidanan Edisi Revisi, Yogjakarta : Nuha Medika

Ratminto dan Winarsih Atik Septi, 2005, Manajemen Pelayanan, Penerbit Yogyakarta : Pustaka Pelajar 
MUQODDIMAH

Sarwono, Prawiharjo, 2009, IImu Kebidanan, Jakarta : Bina Pustaka.

Peraturan Menteri Kesehatan Republik Indonesia Nomor 1464 Tahun 2010 Tentang ljin dan Penyelengaraan Praktik Bidan

Undang-Undang Nomor 36 Tahun 2009 Tentang Kesehatan 